\title{
High lipid perennial ryegrass growth under variable nitrogen, water and carbon dioxide supply
}

\author{
Z.D. BEECHEY-GRADWELL, S. WINICHAYAKUL and N.J. ROBERTS \\ AgResearch Grasslands, Plant Biotechnology, Palmerston North, New Zealand \\ zacbeechey@gmail.com
}

\begin{abstract}
A novel strategy to increase the metabolisable energy content of pasture species has been the development of a GM technology ('High metabolisable energy' or HME), which when expressed in the leaves of perennial ryegrass, increases leaf lipids up to $6-7 \%$ of DW (approximately double 'normal' levels). Remarkably, increased rates of photosynthesis and growth also occur in these plants. The industry strategy is to perform field trials overseas to establish the value proposition for New Zealand. Here, results are presented from preliminary growth-chamber pot trials which reveal the influence of the HME technology on perennial ryegrass growth under different levels of $\mathrm{N}, \mathrm{H}_{2} \mathrm{O}$ and $\mathrm{CO}_{2}$ supply. HME increased perennial ryegrass growth under high $\mathrm{N}$ supply, limiting and non-limiting $\mathrm{H}_{2} \mathrm{O}$ supply, and with ambient and elevated $\mathrm{CO}_{2}$ supply. Possible HME growth mechanisms and their practical implications are discussed. Progress on the 2017 field trial in the USA using offspring from the HME crossing programme is also discussed.
\end{abstract}

Keywords: genetic modification, metabolisable energy, fatty acids, nitrogen, water, carbon dioxide

\section{Introduction}

Perennial ryegrass (Lolium perenne) is the most widelyused pasture species in ruminant farming systems in New Zealand due to its tolerance of frequent grazing and high digestibility. However, the productivity of ruminants fed grass-based diets is constrained by the inefficient conversion of plant energy and protein into animal products (Kingston-Smith \& Theodorou 2000). Perennial ryegrass nutritive value traits such as metabolisable energy (ME) have received little attention from breeders compared with traits related to yield (Chapman et al. 2012). Lipids make an important contribution to forage ME and provide additional environmental benefits in the ruminant diet (Grainger \& Beauchemin 2011).

Progress towards delivering perennial ryegrass with high leaf lipids (Winichayakul et al. 2008) was reported 10 years ago. Since then, a critical innovation leading to long-term lipid elevation in the leaves and roots of the model plant species Arabidopsis thaliana (Arabidopsis) was reported (Roberts et al. 2015; Winichayakul et al. 2013). The key to long term lipid accumulation was the expression of a novel lipid droplet stabilising protein (Cys-oleosin). Oleosin proteins occur naturally within seeds and pollen and encapsulate lipid droplets (LDs). Arabidopsis plants were modified to co-express diacylglycerol O-acyltransferase 1 (DGAT1; the final enzyme in the triacylglycerol (TAG) biosynthesis pathway) and an oleosin with six cysteine residues introduced into its molecular structure. This caused the plants to accumulate high lipids and altered fatty acid (FA) profiles (increased $\mathrm{C} 18: 1$ and $\mathrm{C} 18: 2$ ) (Winichayakul et al. 2013). The authors proposed that disulphide bonds formed between the arms of neighbouring Cys-oleosins on the surface of LDs, crosslinking them. This conferred greater stability to LDs in planta. TAG could accumulate, and the diversion of FAs into stable LDs generated a continuous demand for de novo FA synthesis (Winichayakul et al. 2013). Remarkably, co-expression of DGAT1 and Cys-oleosin gave Arabidopsis a $24 \%$ increase in $\mathrm{CO}_{2}$ assimilation rate and a $50 \%$ increase in shoot growth, relative to the control. This was not observed in plants expressing DGAT1 and the native oleosin (Winichayakul et al. 2013).

Clonal perennial ryegrass plants co-expressing DGAT1 and Cys-oleosin (termed HME perennial ryegrass) have been produced. Given that storage of TAG in the roots is of no agronomic benefit, a useful development of the HME technology in perennial ryegrass has been its expression under light-regulated 'green tissue-specific' promoter sequences. Like Arabidopsis, HME perennial ryegrass shows elevated leaf lipids, altered fatty acid profiles and increased growth. These changes are sustained over a typical perennial ryegrass regrowth interval (3-4 weeks) under repeated mechanical defoliation with a non-limiting nutrient and water supply. The stability of the HME trait in perennial ryegrass shows that HME could deliver the benefits of higher dietary lipids whilst maintaining a low input pastoral farming system.

Presently, the HME trait is being introduced into elite ryegrass cultivars in a breeding programme within AgResearch Ltd and the seed generated from this programme is being used for off-shore field trials. The results from these trials will be used to establish the value proposition for New Zealand. The success of the HME molecular work to date represents an important achievement. Despite this, the suitability of HME for 
adoption into the New Zealand pastoral system remains largely unknown. In part, this is due to our incomplete understanding of the effect of HME on plant growth and metabolism under different conditions. The availability of soil nitrogen ( $\mathrm{N}$; occurring as $\mathrm{NO}_{3}{ }^{-}, \mathrm{NH}_{4}^{+}$or urea) often limits pasture growth, but $\mathrm{N}$ losses from the system are associated with a host of environmental problems (Andrews \& Lea 2013). Rising atmospheric $\mathrm{CO}_{2}$ levels are expected to increase perennial ryegrass growth (Ainsworth et al. 2003), but the associated changes in climate are expected to decrease annual rainfall in important agricultural regions of New Zealand (Orwin et al. 2015). This paper reports on three preliminary growth-cabinet pot trials where the supply to the HME perennial ryegrass of three key plant resources $\left(\mathrm{N}, \mathrm{H}_{2} \mathrm{O}\right.$ and $\mathrm{CO}_{2}$ ) was varied.

\section{Materials and methods}

Replicates in these experiments consisted of isogenic vegetative clones. The wild type control genotype (WT) was untransformed and the HME genotypes were derived from independent WT transformation events which resulted in successful incorporation of the HME construct into their genome. The HME genotypes differed from one another only in the position and copy number of the HME genetic construct.

In the $\mathrm{N}$ trial, the regrowth and $\mathrm{N}$ assimilation of a transgenic 'medium lipid' (ML) HME perennial ryegrass genotype (with approximately $5.5 \%$ leaf fatty acid content) was compared to its pre-transformed control genotype (WT) under 1-10 mM N supply added as either $\mathrm{NO}_{3}^{-}, \mathrm{NH}_{4}^{+}$or urea-N. In the $\mathrm{H}_{2} \mathrm{O}$ trial, the regrowth and water use efficiency of ML and WT were compared when water was withheld from plants for a regrowth cycle. In the $\mathrm{CO}_{2}$ trial, the regrowth of ML, WT and a 'low lipid' (LL) and 'high lipid' (HL) genotype (with approximately 4.5 and $6.5 \%$ leaf fatty acid content, respectively) were compared under ambient (400 ppm) and elevated (760 ppm) atmospheric $\mathrm{CO}_{2}$.

\section{Plant establishment and pot design}

In all trials, replicates were made by splitting mature 'first generation' HME and WT control plants into plantlets, cutting root and shoot length to $5 \mathrm{~cm}$ and transplanting into pots. The plantlets were then given approximately 4 weeks to establish a root system before defoliating $5 \mathrm{~cm}$ above the soil surface and random allocation to different experimental treatments. The initial plantlet tiller number differed in each of the trials to suit the pot design. In the $\mathrm{N}$ trial, $1.3 \mathrm{~L}$ pots containing a 'low N' potting mix were used. Seven tillers per plantlet were established under a limiting $\mathrm{N}$ supply ( $2 \mathrm{mM} \mathrm{KNO}_{3}$ ). In the $\mathrm{H}_{2} \mathrm{O}$ trial, tall cylindrical $(5 \mathrm{~L})$ pots containing a 1:1 mix of sand and potting mix were used. Fifteen tiller/plantlet were established under non-limiting nutrient and water supply. In the $\mathrm{CO}_{2}$ trial, $1.6 \mathrm{~L}$ pots containing washed sand were used. Four tillers per plantlet were established under a limiting $\mathrm{N}$ supply $\left(2 \mathrm{mM} \mathrm{KNO}_{3}\right)$.

\section{Growth environment}

In the $\mathrm{N}$ trial and $\mathrm{H}_{2} \mathrm{O}$ trial, plants were grown under a $22 / 18{ }^{\circ} \mathrm{C}$ day/night temperature regime in a controlled temperature room at Grasslands, Palmerston North. The lighting system consisted of 600W LED lights (ledgrowlights, Hamilton, New Zealand) and the photoperiod was $10 \mathrm{~h}$. In the $\mathrm{CO}_{2}$ trial, plants were grown under a $20 / 15{ }^{\circ} \mathrm{C}$ day/night temperature regime in two Conviron BDW growth chambers in the Lincoln University Biotron. The lighting system consisted of $400 \mathrm{~W}$ metal halide bulbs (Venture Ltd., Mount Maunganui, New Zealand) in combination with soft tone, soft white $100 \mathrm{~W}$ incandescent bulbs (Philips, Auckland, New Zealand) and the photoperiod was $12 \mathrm{~h}$.

\section{Experimental treatments during regrowth}

From the beginning of the regrowth period different experimental treatments were imposed. In the $\mathrm{N}$ trial, pots were flushed every second day with $100 \mathrm{ml}$ of solutions of $0,1,2.5,5,7.5$ or $10 \mathrm{mM}$ concentration of the appropriate $\mathrm{N}$ form. Potassium concentrations were balanced with $\mathrm{K}_{2} \mathrm{SO}_{4}$ in all treatments. In the $\mathrm{H}_{2} \mathrm{O}$ trial, water was withheld from half of the pots while water was maintained near the pot-holding capacity for the other half $(\mathrm{n}=3)$. In the $\mathrm{CO}_{2}$ trial, half of the pots were shifted into a second growth room with identical settings to the first, except the $\mathrm{CO}_{2}$ level in the second growth room was maintained at $760 \mathrm{ppm}$ with G214 food grade $\mathrm{CO}_{2}$ (BOC, Auckland, New Zealand). The $\mathrm{CO}_{2}$ levels in both the growth rooms were measured continuously using PP Systems WMA-4 Gas Analysers (John Morris Scientific, Auckland, New Zealand). The pots were flushed every second day with $250 \mathrm{ml}$ of solutions containing $5 \mathrm{mM} \mathrm{N}$, as either $\mathrm{NO}_{3}{ }^{-}, \mathrm{NH}_{4}{ }^{+}$or a $4: 1 \mathrm{NO}_{3}^{-}: \mathrm{NH}_{4}^{+} \operatorname{mix}(\mathrm{n}=4-6)$.

\section{Harvest, tissue composition and statistical analysis}

In all experiments, plants were destructively harvested after 4-5 weeks regrowth and oven-dried at $60^{\circ} \mathrm{C}$ for 4-6 days. The DW of leaves, stubble and roots were then determined. In the $\mathrm{N}$ trial, selective treatments were ground and analysed for FA content and composition, $\% \mathrm{~N}$, and $\mathrm{NO}_{3}{ }^{-}$content. In the $\mathrm{H}_{2} \mathrm{O}$ trial, only the leaf regrowth DW was determined and the change in the weight of the pots was used to determine plant water use. In the $\mathrm{CO}_{2}$ trial, ground material was analysed for FA content and composition. Results were analysed by Student's t-test, two or three-way ANOVA using the $\mathrm{R}^{2}$ software. Shoot DW data from the $\mathrm{CO}_{2}$ trial was square 

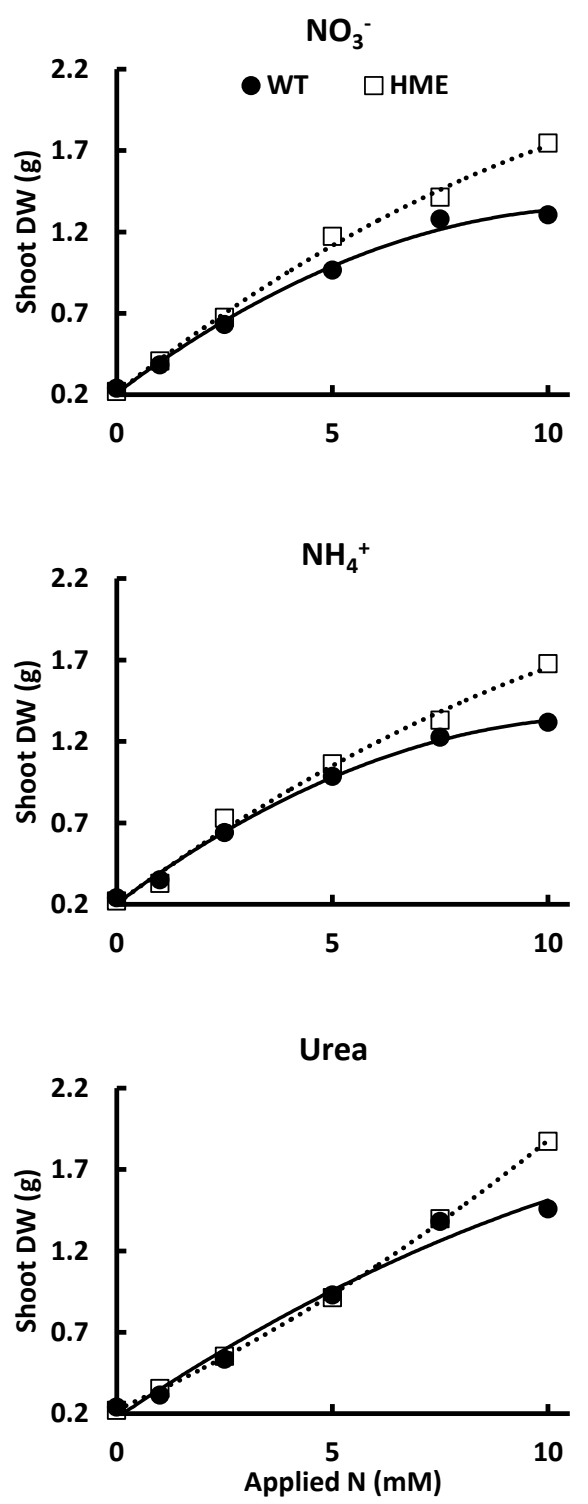

Figure 1 Effect of $1-10 \mathrm{mM} \mathrm{NO}_{3}^{-}, \mathrm{NH}_{4}^{+}$and urea supply on shoot dry weight (DW) of a 'Wild type control' (WT) genotype and medium lipid 'High metabolisable energy' (HME) genotype of perennial ryegrass, regrown from seven tillers/plantlet. Data points represent means $(n=4) . N=$ Nitrogen, $m M=$ Millimoles.

root transformed to meet the ANOVA assumption of normality. All effects discussed have a probability of $\mathrm{P}<0.05$.

\section{Results}

\section{Growth, $\mathbf{N}$ assimilation and NUE}

In the $\mathrm{N}$ trial, ML shoot DW increased across the entire $\mathrm{N}$ supply range regardless of $\mathrm{N}$ form, whereas
WT shoot DW did not significantly increase beyond $7.5 \mathrm{mM} \mathrm{N}$ supply. At $10 \mathrm{mM} \mathrm{N}$ supply, ML shoot DW was $27-34 \%$ greater $(\mathrm{P}<0.0001)$ (Figure 1) while root DW was $25-45 \%$ greater $(\mathrm{P}<0.01)$ than in the WT (data not shown). Total plant $\mathrm{N} \%$ and the shoot to root ratio was lower for plants supplied with $\mathrm{NO}_{3}{ }^{-}$than with $\mathrm{NH}_{4}{ }^{+}$ or urea $(\mathrm{P}<0.05)$ but did not differ between the WT control and ML (similar $\mathrm{N}$ utilisation efficiency and biomass partitioning) (data not shown). Total plant $\mathrm{N}$ assimilation at $10 \mathrm{mM} \mathrm{N}$ supply estimated according to the formula ((N\% - $\left.\left.\mathrm{NO}_{3}{ }^{-} \%\right) \times \mathrm{DW}\right)$ was greater for ML $(\mathrm{P}<0.0001)$ (increased $\mathrm{N}$ uptake efficiency) (data not shown).

\section{Leaf fatty acids}

In the $\mathrm{N}$ trial, FAs accumulated in the leaves of both WT and ML up until the $\mathrm{NO}_{3}{ }^{-}$supply required for near-optimal growth $(7.5$ and $10 \mathrm{mM}$ for WT and ML, respectively). Here the FA concentration reached approximately 3.25 and $5 \%$ of DW for WT and ML, respectively (Figure 2). The $\mathrm{NO}_{3}{ }^{-}$supply level at which ML leaf FA concentration exceeded the maximum WT leaf FA concentration was $2.5 \mathrm{mM}$ (i.e. more FAs with $1 / 3$ the $\mathrm{NO}_{3}{ }^{-}$supply) $(\mathrm{P}<0.05)$. ML contained a greater proportion of $\mathrm{C} 18: 1$ and $\mathrm{C} 18: 2$ and a smaller proportion of $\mathrm{C} 18: 3$ than WT $(\mathrm{P}<0.0001)$. Root FA concentration did not differ between ML and the WT control (data not shown).

\section{Leaf water content and WUE}

In the $\mathrm{N}$ trial, leaf $\mathrm{H}_{2} \mathrm{O} \%$ was influenced by $\mathrm{N}$ supply and the form of $\mathrm{N}$. It increased up until $7.5 \mathrm{mM} \mathrm{N}$ supply and was highest in plants supplied with $\mathrm{NO}_{3}^{-}$, followed by $\mathrm{NH}_{4}^{+}$then urea. ML leaf $\mathrm{H}_{2} \mathrm{O} \%$ was consistently higher than in the WT control $(\mathrm{P}<0.0001)$, and there was a leaf $\mathrm{H}_{2} \mathrm{O} \%$ genotype $x \mathrm{~N}$ form interaction $(\mathrm{P}<0.05)$ because the increase in ML leaf $\mathrm{H}_{2} \mathrm{O} \%$ was greater with $\mathrm{NO}_{3}{ }^{-}$and urea than with $\mathrm{NH}_{4}^{+}$(data not shown).

In the $\mathrm{H}_{2} \mathrm{O}$ trial, water deficit substantially limited perennial ryegrass regrowth. ML attained greater regrowth than the WT control under both limiting and non-limiting water supply $(\mathrm{P}<0.0001)$ (Figure $3 \mathrm{a})$ and regrowth WUE (DW/water used) was $16 \%$ higher for ML $(\mathrm{P}<0.05)$ (Figure $3 \mathrm{c})$. There was also a genotype $\mathrm{x}$ water-supply interaction because relative to wellwatered controls, limiting the water supply decreased regrowth more for ML (132\%) than the WT control $(110 \%)(\mathrm{P}<0.0001)$. ML also depleted soil water at a rate $30 \%$ faster than the WT control $(\mathrm{P}<0.01)$ (Figure $3 b)$.

\section{Shoot growth response to elevated $\mathrm{CO}_{2}$}

Increasing the atmospheric $\mathrm{CO}_{2}$ concentration from 400 to $760 \mathrm{ppm}$ increased total shoot DW in both WT control and HME plants, regardless of leaf lipid level 

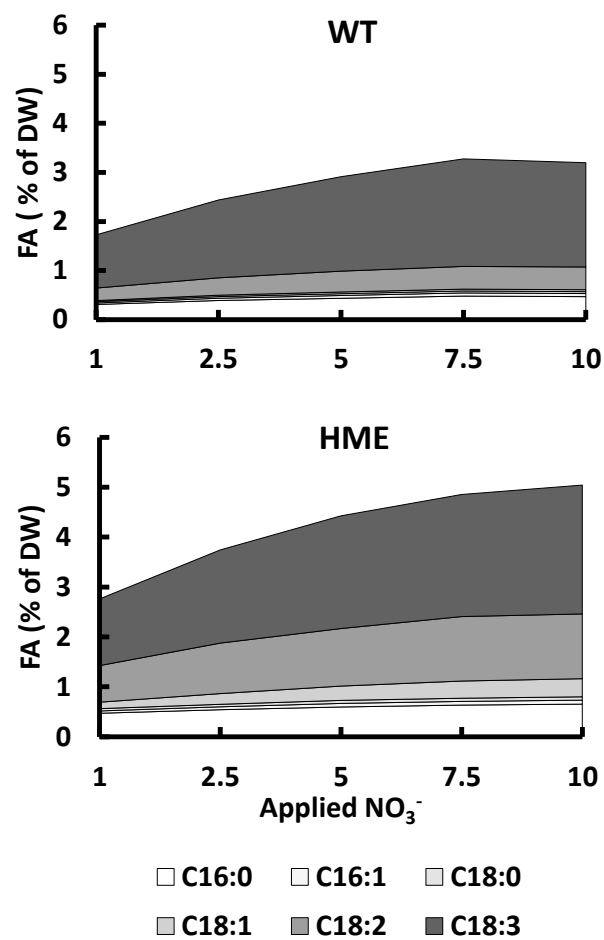

Figure 2 Effect of 1-10 $\mathrm{mM} \mathrm{NO}_{3}^{-}$supply on leaf fatty acid content and composition of a 'Wild type control' (WT) genotype and medium lipid 'High metabolisable energy' (HME) genotype of perennial ryegrass, regrown from seven tillers per plantlet. Data points represent means $(n=4)$. DW = Dry weight, $\mathrm{FA}$ = fatty acids, composed of; palmitic acid (C16:0), palmitoleic acid (C16:1), stearic acid (C18:0), oleic acid (C18:1), linoleic acid (C18:2) and linolenic acid (C18:3).

$(\mathrm{P}<0.001)$. Shoot $\mathrm{DW}$ decreased in the order $\mathrm{LL}>\mathrm{ML}>$ WT $>$ HL $(\mathrm{P}<0.05)$ under both levels of $\mathrm{CO}_{2}$ supply (Figure 4). When the regrowth response to increasing atmospheric $\left.\mathrm{CO}_{2} ;\left(\mathrm{DW}_{\text {elevated }}-\mathrm{DW}_{\text {ambient }}\right) / \mathrm{DW}_{\text {ambient }}\right)$ was determined, the HL genotype appeared to be more responsive to elevated $\mathrm{CO}_{2}$, however, this effect was not significant.

It should be noted that on two occasions, comparisons of the regrowth may have been confounded by plant size differences that developed during the establishment phase. In the $\mathrm{H}_{2} \mathrm{O}$ trial, ML establishment leaf growth was $40 \%$ greater than the WT. In the $\mathrm{CO}_{2}$ trial, LL establishment leaf growth was 35,70 and $98 \%$ greater than WT, ML and HL, respectively.

\section{Discussion}

Supply of three key plant resources $\left(\mathrm{N}, \mathrm{H}_{2} \mathrm{O}\right.$ and $\left.\mathrm{CO}_{2}\right)$ was varied. Increased growth in the HME perennial ryegrass enhanced the capacity for uptake of each resource. Importantly, HME (with medium lipids) did

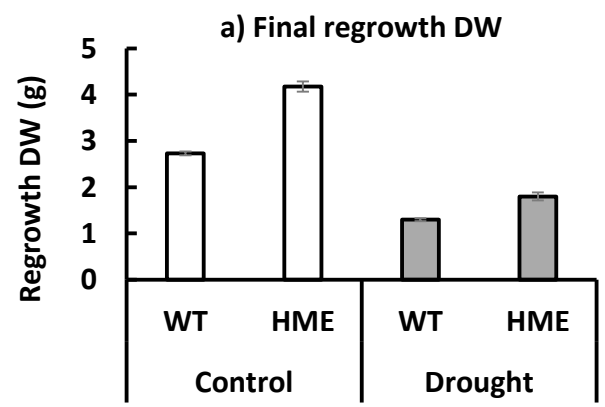

b) Cumulative plant WU
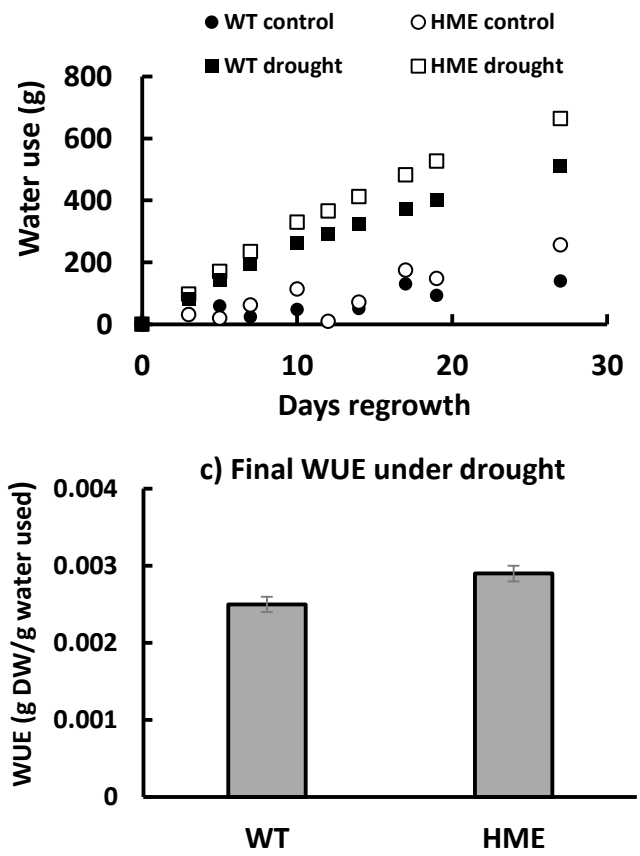

Figure 3 Effect of withholding water for a regrowth cycle on; a) final regrowth dry weight (DW), b) water use (WU) and c) water use efficiency (WUE) of a 'Wild type control' (WT) genotype and medium lipid 'High metabolisable energy' (HME) genotype of perennial ryegrass, regrown from fifteen tillers/ plantlet. Bars represent means and error bars represent standard error $(n=3)$.

not penalise growth under a limited supply of any one resource. Since an expected trade-off between plant growth and high leaf lipids $(6.5 \% \mathrm{DW})$ occurs (Figure 4 ), the following discussion focuses on HME with medium leaf lipids (ML).

It has been speculated that the increase in HME growth may relate to a ' $\mathrm{CO}_{2}$ recycling' mechanism associated with elevated de novo FA synthesis in green tissues (Winichayakul et al. 2013). This hypothetical internal $\mathrm{CO}_{2}$-generating mechanism (which could cause increased plant growth) predicts that HME growth 


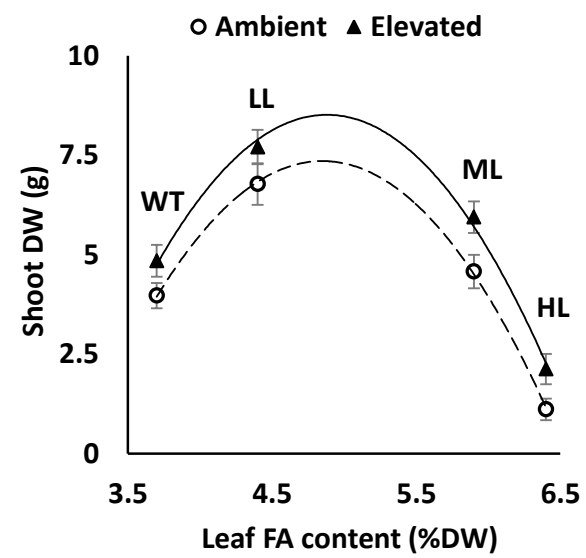

Figure 4 Effect of increasing the atmospheric $\mathrm{CO}_{2}$ concentration from $400 \mathrm{ppm}$ (Ambient) to $760 \mathrm{ppm}$ (Elevated) on the shoot DW of a 'Wild type control' (WT) perennial ryegrass genotype and three independently transformed 'High metabolisable energy' (HME) genotypes containing low, medium and high leaf lipids, regrown from four tillers/ plantlet. Data points represent means and error bars represent standard error of plants supplied with $5 \mathrm{mM}$ concentration of three different $\mathrm{N}$ forms $(n=12-18)$.

should be comparatively less responsive to increased external $\mathrm{CO}_{2}$ supply. However, $\mathrm{ML}$ attained greater regrowth than the WT control under both ambient and elevated $\mathrm{CO}_{2}$. This suggests that like other grasses, HME will benefit from $\mathrm{CO}_{2}$ fertilisation and that mechanism(s) other than ' $\mathrm{CO}_{2}$ recycling' must also be important for the increase in HME growth. The increase in $\mathrm{HME}$ leaf $\mathrm{H}_{2} \mathrm{O} \%$ warrants further investigation as this trait could enhance leaf expansion and growth. Another process being studied is whether the diversion of fixed carbon into lipid droplets alters the leaf's sink to source transition during early regrowth (Turner et al. 2001).

There was a concern that nitrogen supplied in a reduced form (e.g. $\mathrm{NH}_{4}^{+}$or urea) was needed for maximum HME growth, and that $\mathrm{NO}_{3}{ }^{-}$supply would limit HME growth. Specifically, it was predicted that the high rates of FA synthesis and $\mathrm{CO}_{2}$ fixation would inhibit shoot $\mathrm{NO}_{3}{ }^{-}$assimilation $\left(\mathrm{NO}_{3}{ }^{-} \rightarrow\right.$ amino acids) (Bloom et al. 2012). However, ML attained greater regrowth and total $\mathrm{N}$ assimilation than the WT control under high $\mathrm{N}$ regardless of whether $\mathrm{N}$ was supplied as $\mathrm{NO}_{3}^{-}, \mathrm{NH}_{4}^{+}$or urea. Given that the majority of ryegrass $\mathrm{NO}_{3}{ }^{-}$assimilation occurs in the shoot at high $\mathrm{NO}_{3}{ }^{-}$supply (Andrews et al. 1992) this suggests that high shoot FA synthesis and $\mathrm{CO}_{2}$ fixation can occur in ryegrass without significantly inhibiting shoot $\mathrm{NO}_{3}^{-}$ assimilation. From a practical perspective, $\mathrm{N}$ supply (rather than $\mathrm{N}$ form) is of primary importance for HME growth and FAs. HME could increase nitrogen use efficiency (NUE) by increasing $\mathrm{N}$ uptake under high $\mathrm{N}$ loads (e.g. urine patches).

The increase in HME water use (WU) was a result of the greater plant size and the combined effect of increased leaf growth and leaf $\mathrm{H}_{2} \mathrm{O} \%$ which likely caused a substantial increase in transpiring leaf area. The increase in HME WUE (DW/water used) could relate to greater intrinsic water use efficiency (iWUE: $\mathrm{C}$ gain $/ \mathrm{H}_{2} \mathrm{O}$ lost) associated with internal $\mathrm{CO}_{2}$ recycling (Winichayakul et al. 2013). Determining how increased HME WU and WUE influence agronomic performance under drought will require further testing (Blum 2005).

It is expected that the HME technology holds potential for valuable future application in New Zealand's pastoral agriculture. For clarification, the primary benefit of HME is expected to come from increasing the energy density of pasture. Successfully translating the growth effect to the field will be an added benefit and will require that the mechanism(s) are compatible with growth in a sward under variable, non-optimal conditions. A pilot field trial was successfully completed in July 2017 in the USA, using an LL HME ryegrass. The trial aimed primarily to test the suitability of the field trial location and to ensure that the regulatory requirements were met. Preliminary photosynthesis measurements indicated that the LL HME ryegrass had $10 \%$ greater photosynthesis than the WT control. A larger-scale trial is occurring in 2018 and the results will be presented in due course.

\section{Conclusion}

The HME technology has the potential to deliver the benefits of higher dietary lipids in the ruminant diet whilst maintaining a low-input pastoral farming system. Preliminary growth-cabinet pot trials show that successful translation of the HME growth effect to the field could increase ryegrass NUE and WUE, further enhancing the potential benefits of this technology. Progress in our understanding of the HME growth mechanisms will help to predict under what conditions these traits could translate to the field. The industry strategy is to perform field trials overseas to establish the value proposition for New Zealand.

\section{ACKNOWLEDGEMENTS}

We would like to thank Mitchell Andrews for advice on the experimental work and Greg Bryan for help with preparing this manuscript.

\section{REFERENCES}

Ainsworth, E.; Davey, P.; Hymus, G.; Osborne, C.; Rogers, A.; Blum, H.; Nösberger, J.; Long, S. 2003. Is stimulation of leaf photosynthesis by elevated carbon dioxide concentration maintained in the long term? A test with Lolium perenne grown for 10 years at 
two nitrogen fertilization levels under Free Air $\mathrm{CO}_{2}$ Enrichment (FACE). Plant, Cell and Environment 26: 705-714.

Andrews, M.; Lea, P. 2013. Our nitrogen 'footprint': the need for increased crop nitrogen use efficiency. Annals of Applied Biology 163: 165-169.

Andrews, M.; Morton, J.; Lieffering, M.; Bisset, L. 1992. The partitioning of nitrate assimilation between root and shoot of a range of temperate cereals and pasture grasses. Annals of Botany 70: 271-276.

Bloom, A.J.; Asensio, J.S.R.; Randall, L.; Rachmilevitch, S.; Cousins, A.B.; Carlisle, E.A. 2012. $\mathrm{CO}_{2}$ enrichment inhibits shoot nitrate assimilation in $\mathrm{C} 3$ but not $\mathrm{C} 4$ plants and slows growth under nitrate in C3 plants. Ecology 93: 355-367.

Blum, A. 2005. Drought resistance, wateruse efficiency, and yield potential-are they compatible, dissonant, or mutually exclusive? Australian Journal of Agricultural Research 56: 1159-1168.

Chapman, D.; Bryant, J.; McMillan, W.; Khaembah, E. 2012. Economic values for evaluating pasture plant traits. Proceedings of the New Zealand Grassland Association 74: 209-216.

Grainger, C.; Beauchemin, K. 2011. Can enteric methane emissions from ruminants be lowered without lowering their production? Animal Feed Science and Technology 166: 308-320.

Kingston-Smith, A.; Theodorou, M. 2000. Tansley
Review No. 118. Post-ingestion metabolism of fresh forage. The New Phytologist 148: 37-55.

Orwin, K.H.; Stevenson, B.A.; Smaill, S.J.; Kirschbaum, M.U.; Dickie, I.A.; Clothier, B.E.; Garret, L.G.; Weerden, T.J.; Beare, M.J.; Curtin, D. 2015. Effects of climate change on the delivery of soil-mediated ecosystem services within the primary sector in temperate ecosystems: a review and New Zealand case study. Global Change Biology 21: 2844-2860.

Roberts, N.J.; Scott, R.W.; Winichayakul, S.; Roldan, M. 2015. Modified oil encapsulating proteins and uses thereof. Accessed: 16th July 2018 https://www. lens.org/lens/patent/WO 2011053169 A1

Turner, L.B.; Humphreys, M.O.; Cairns, A.J.; Pollock, C.J. 2001. Comparison of growth and carbohydrate accumulation in seedlings of two varieties of Lolium perenne. Journal of Plant Physiology, 158: 891-897.

Winichayakul, S.; Cookson, R.; Scott, R.; Zhou, J.; Zou, X.; Roldan, M.; Richardson, K.; Roberts, N. 2008. Delivery of grasses with high levels of unsaturated, protected fatty acids. Proceedings of the New Zealand Grassland Assocation 70: 211-216.

Winichayakul, S.; Scott, R.W.; Roldan, M.; Hatier, J.H.B.; Livingston, S.; Cookson, R.; Curan, A.C.; Roberts, N.J. 2013. In vivo packaging of triacylglycerols enhances Arabidopsis leaf biomass and energy density. Plant Physiology 162: 626-639. 